\title{
The Benefits of the MOE/MAR Implementation: A Quantitative Approach
}

\author{
Nick Zamora, Michael Carter, Stephanie Saull-McCaig and Joe Nguyen
}

\section{Introduction}

Once the decision was made to implement an electronic medication order entry and medication administration record (MOE/ MAR) system at the University Health Network (UHN), a significant question soon emerged: How would UHN be able to determine if the project had indeed accomplished its stated objectives of improving patient safety and the medication ordering and processing cycle?

With this in mind, UHN enlisted the assistance of researchers who would conduct a quantitative study to measure the impact and benefits of the new system. While seemingly straightforward, this evaluation was made more challenging by the diverse expectations of MOE/MAR.

This article reports on the results of UHN's multi-year study looking at the impact of MOE/MAR. In our overview, we examine such elements as the methodology used as well as the challenges and constraints faced by the team. We also examine the following: the types of lessons learned during MOE/MAR's implementation; the effectiveness of teamwork; and the impact of external resources upon the project.

\section{Why Study the Benefits?}

The old saw, you can't manage what you can't measure, was the orienting principle behind the MOE/MAR evaluation from conception to implementation. The study's objective was to measure the impact of implementing MOE/MAR on patient safety, clinical workflow and the quality of patient care. We developed a number of specific performance indicators from which we expected definite results. We soon discovered there were very few studies, either at the UHN or anywhere else, that indicated consistent results regarding the impact of MOE/MAR. Some studies, in fact, indicated mixed or conflicting results. Up to this point, UHN had only conducted rudimentary benefits measurement evaluations on its IT projects as part of its overall project management function. Our experience suggested that this was common in the healthcare sector and provided us with yet another reason to move forward with our more comprehensive evaluation.

The need for a benefits/measurement study of MOE/MAR was made clear by UHN leadership. If the healthcare organization was committing significant time as well as human and financial resources toward implementing this major change initiative, it was essential to gather data and provide evidencebased research to justify to UHN decision-makers (and other healthcare organizations contemplating similar projects) that such investments were indeed worth the effort. Without such information it would not be possible to demonstrate MOE/ MAR's effectiveness.

A comprehensive, multi-year study would provide ongoing information to the implementation team, users and administration that the project was proceeding according to plan. Study data would also be used to measure the implementation progress and any adjustments needed along the way to improve the process - allowing for the cycle of ongoing quality improvement at UHN. 


\section{Background and Overview}

UHN's Shared Information Management Systems (SIMS) department had engaged an external healthcare consulting group to advise and support the overall MOE/MAR project. The lead consultant from the firm strongly advocated the need for a UHN leader-supported benefits/measurement study and engaged a faculty researcher at a local university to join him on the MOE/MAR study.

The researcher assembled a group of his undergraduate summer students and former graduates in industrial engineering to join the project team. From the outset, the students were integrated into the overall team structure rather than assigned tasks and sent off to work (and subsequently submitting reports of their findings). This was a successful strategy, as the students gained practical experience in their field and the organization (UHN) established a working relationship with the university that could be continued on future projects.

In addition, the team also convened a benefits realization steering committee that comprised the key stakeholders on the project to determine objectives and research questions.

\section{The "Benefits" of Our Benefits Study}

It was recognized that empirical evidence generated through the study could help validate (or challenge) the commitment to MOE/MAR. And, should MOE/MAR prove successful, it would positively affect attitudes and perceptions, supporting future implementations. Lastly, conducting the study reinforced a "culture of accountability" at the hospital so that the impact and benefits of future projects could be properly analyzed in a systematic and quantifiable way. By this time, SIMS staff had already incorporated a rigorous benefits/measurement framework into several other projects.

One of the key reasons we successfully secured support for the study was the promise of the ability to quickly show results. For example, as data were collected during the time spent on a unit with a particular group that had implemented MOE/MAR, we shared these data weekly (sometimes more often) with the groups so that each group could see what improvements there were on their specific units. Often, these included reductions in transcription errors in medication orders or change in time spent on recording medication orders into the MAR. Stakeholders were able to readily see changes that were both tangible and positive.

\section{Methodology and Approach}

A steering committee with diverse representation was established to oversee the study. To be consistent with the project management methodology in terms of the overall process, a project charter and detailed work-plan was devised and subsequently implemented. In this manner, the benefits measurement process could be separately tracked by the SIMS' Project Management Office to ensure it met timelines and project expectations relative to the MOE/MAR implementation.

Our approach to assessing the benefits of MOE/MAR proceeded in four stages:

\section{Select Key Metrics and Indicators}

- Identify the right indicators to address the stated objectives of your MOE/MAR project. For example, is it patient safety or process improvements that the organization would most like to achieve?

- Select indicators that are quantifiable, easy to collect and yield the most significant results. Recognize that clinical chart audits are very resource-intensive and require experienced clinician resources.

\section{Identify Data Sources}

- For the UHN study, we developed our metrics around three different types of available data sources: Chart Audits, Time-Motion Study and Electronic Reporting (Data Warehouse).

\section{Collect/Tabulate Data}

- Develop charts and tables that are accurate and easily interpreted so that immediate actions can be developed.

\section{Communicate Results}

- Develop a communication mechanism to share results and feedback with stakeholders and users on a regular basis.

After documenting the medication ordering process (see Figure 1), we developed indicators that we felt would best demonstrate the impact of the MOE/MAR technology. The list of key indicators measured in the study is consolidated in Table 1. During this phase we were always mindful to choose indicators that would be meaningful and applicable for clinical and hospital executive decision-making.

\section{Results and Findings}

The data for this study were collected over a two-year period (May 2004 to May 2006) for all eight clinical service clusters that were implemented at UHN. These include both medical and surgical patient care areas, which exhibit different detailed medication ordering cycle workflows (see Table 2).

\section{Technology Adoption}

From the CPOE rate of $89 \%$, we can conclude that the adoption of the technology is high; many institutions do not see this level over $50 \%$. However, based on our surveys after a two-month implementation process, the clinicians (MD, $\mathrm{RN}, \mathrm{Rx}$ ) still had mixed feelings about the system, as they were still moving down the learning curve.

\section{Quality of Care and Patient Safety}

The ability to use clinical-decision support was a significant benefit of MOE/MAR that could not have been realized with a 
Figure 1. Medication order processing cycle and indicators

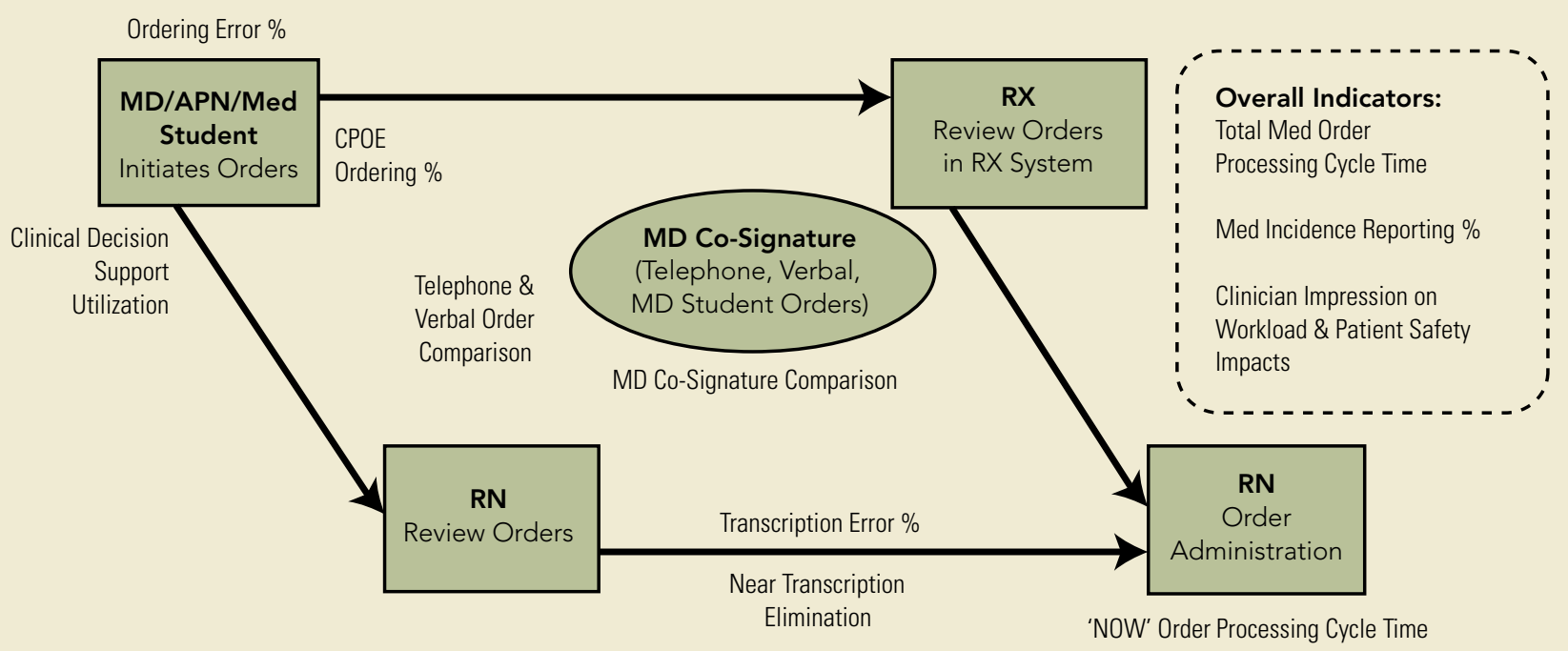

(MD = Physicians; $A P N=$ Advance Practice Nurse; RX = Pharmacists; RN = Nurse)

(Please refer to Table 1 for detailed indicator definitions and explanations.)

paper-based system. With an average of 4,000 interaction alerts "fired" per month, these numbers show that UHN is heading in the right direction vis-à-vis utilizing technology to further bolster patient safety. However, the mere fact that more alerts are being fired in itself is not necessarily a good thing. Over time the alerts could be considered a nuisance and eventually be ignored by a physician. This could not only reduce the usefulness of a potentially effective decision-support tool but could also lead to an increase in patient safety risks for patients. To ensure that this does not happen, SIMS and its clinical advisors continuously evaluate the alerts programmed into the system to ensure they are accurate and useful, as well as monitor the acknowledgment rate of the alert recipients.

The near complete reduction of transcription errors in both the chart audit study and the reported medication incidences has allowed us to establish the value of the MOE/MAR system and speak directly to patient safety. In addition, non-measured benefits (because there were no base-rate data) were realized from the system, namely, $100 \%$ complete and legible orders.

\section{Clinical Workflow}

The overall medication ordering process and turnaround time of the "Now" dose markedly decreased with the implementation of the MOE/MAR system. This creates an improved patient care environment due to fewer medication delays.

UHN has historically attempted to decrease the number of verbal and telephone orders. In this regard MOE/MAR has been able to facilitate a $75 \%$ decrease in these types of orders, thereby allowing the physicians and nurse practitioners to directly enter their own orders. This has noticeably reduced miscommunication while increasing accountability.

Finally, customized order sets - tailored to each practice area - and offsite accessibility have been valuable to address the challenges posed by residents and clinical fellows who rotate throughout an academic teaching hospital.

\section{Policy Adherence}

Throughout the project, we have seen a shift in accountability. The introduction of the electronic ordering and documentation of medication has created a shift in medication reporting practice. We have a seen a $150 \%$ increase in overall reported medication incidents. This is a positive step towards UHN's stated goal of "transparent" patient care practice, and is also good for the overall organization.

We have also seen an almost $97 \%$ co-signature rate for verbal and telephone orders. Thus, UHN has almost achieved its goal of $100 \%$ co-signed orders.

\section{Process Improvements}

Since the results of the study were shared and communicated on an ongoing basis after every cluster implementation, we were able to utilize the data to identify areas of improvement and our approach for the subsequent rollouts. This allowed us to provide an ongoing cycle of improvements, using a methodology similar to the PDSA cycle (Plan/Do/See/Act) created by the Institute for Healthcare Improvement. 
Table 1. Key indicators and metrics

\begin{tabular}{|c|c|c|c|}
\hline Metric/Indicator & Definition & Methodology/Data Source & $\begin{array}{l}\text { Indication (Impacts Post- } \\
\text { implementation) }\end{array}$ \\
\hline $\begin{array}{l}\text { Ordering \& transcription } \\
\text { error \% }\end{array}$ & $\begin{array}{l}\text { - Ordering errors include incorrect dosage, orders against } \\
\text { medication allergy, duplicate orders, missing key order } \\
\text { elements (e.g., dose, route), incorrect abbreviations } \\
\text { - Transcription errors include incorrect medication } \\
\text { transcription, missed transcription and incorrect date } \\
\text { transcribed } \\
\text { - Percentage of ordering and transcription errors detected } \\
\text { over total number of orders sampled }\end{array}$ & Chart audit (sampling) & $\begin{array}{l}\text { Potential ordering \& } \\
\text { transcription errors eliminated }\end{array}$ \\
\hline $\begin{array}{l}\text { Major vs. minor medication } \\
\text { ordering \& transcription error }\end{array}$ & $\begin{array}{l}\text { - Same as above indicator, categorized by major vs. minor } \\
\text { - Mategories } \\
\text { - Allergy to med } \\
\text { - Incorrect dosage } \\
\text { - Duplicate medication orders } \\
\text { - Missing key components (e.g., dose, route) } \\
\text { - Missed transcription } \\
\text { - Incorrect transcription } \\
\text { - Minor errors: } \\
\text { - Incorrect abbreviations } \\
\text { - Incorrect date transcribed }\end{array}$ & Chart audit (sampling) & $\begin{array}{l}\text { Potential ordering \& } \\
\text { transcription errors eliminated }\end{array}$ \\
\hline $\begin{array}{l}\text { Medication incident reporting } \\
\text { frequency }\end{array}$ & $\begin{array}{l}\text { - Comparison of all reported medication incidents collected } \\
\text { pre-and post-implementation (six-month period pre-, and } \\
\text { three-month period post-implementation) }\end{array}$ & Medication incident reporting & $\begin{array}{l}\text { Potential medication errors } \\
\text { eliminated; accountability and } \\
\text { reporting culture shift in an } \\
\text { electronic environment }\end{array}$ \\
\hline Transcription error reported & $\begin{array}{l}\text { - Comparison of transcription error percentage through } \\
\text { reported medication incidents pre- and post-implementation }\end{array}$ & Medication incident reporting & $\begin{array}{l}\text { Potential medication errors } \\
\text { eliminated post-MOE/MAR; } \\
\text { accountability and reporting } \\
\text { culture shift in an electronic } \\
\text { environment }\end{array}$ \\
\hline $\begin{array}{l}\text { Clinician impression on } \\
\text { patient safety }\end{array}$ & $\begin{array}{l}\text { - Patient safety impression rating through user surveys post- } \\
\text { implementation }\end{array}$ & Survey response & Overall qualitative feedback \\
\hline $\begin{array}{l}\text { Total medication order } \\
\text { processing cycle time }\end{array}$ & $\begin{array}{l}\text { - Time from physician order creation/entry to pharmacy or } \\
\text { nursing order verification (whichever occurs last) }\end{array}$ & $\begin{array}{l}\text { Time-motion study (pre), data } \\
\text { warehouse (post) }\end{array}$ & $\begin{array}{l}\text { Timeliness of medication } \\
\text { processing }\end{array}$ \\
\hline $\begin{array}{l}\text { "Now" order processing cycle } \\
\text { time }\end{array}$ & $\begin{array}{l}\text { - Time from physician creation/entry to patient administration } \\
\text { of "Now" dose }\end{array}$ & $\begin{array}{l}\text { Time-motion study (pre), data } \\
\text { warehouse (post) }\end{array}$ & Timeliness of "Now" orders \\
\hline $\begin{array}{l}\text { Telephone \& verbal order } \\
\text { comparison }\end{array}$ & $\begin{array}{l}\text { - Percentage of telephone \& verbal orders detected over total } \\
\text { number of medications ordered }\end{array}$ & $\begin{array}{l}\text { Chart audit (pre), data } \\
\text { warehouse (post) }\end{array}$ & $\begin{array}{l}\text { Promotion of direct physician/ } \\
\text { acute nurse practitioner } \\
\text { orders }\end{array}$ \\
\hline $\begin{array}{l}\text { MD co-signature rate } \\
\text { comparison }\end{array}$ & $\begin{array}{l}\text { - Percentage of signed "co-signature required" orders } \\
\text { detected over total number of medications ordered }\end{array}$ & $\begin{array}{l}\text { Chart audit (pre), data } \\
\text { warehouse (post) }\end{array}$ & $\begin{array}{l}\text { Promotion of co-signature and } \\
\text { adherence to policy }\end{array}$ \\
\hline $\begin{array}{l}\text { Clinician impression of MOE/ } \\
\text { MAR regarding workload }\end{array}$ & $\begin{array}{l}\text { - Workload impression rating through user surveys post- } \\
\text { implementation }\end{array}$ & Survey response & Qualitative feedback \\
\hline $\begin{array}{l}\text { Clinical decision support } \\
\text { utilization }\end{array}$ & $\begin{array}{l}\text { - Number of medication clinical decision support alerts } \\
\text { "fired" over MOE/MAR system post-implementation } \\
\text { - Alerts include duplicate orders, allergy interaction, limited } \\
\text { drug-drug interaction }\end{array}$ & Data warehouse (post) & $\begin{array}{l}\text { Promotion of medication } \\
\text { safety - utilization of clinical } \\
\text { decision support tools }\end{array}$ \\
\hline CPOE percentage & $\begin{array}{l}\text { - Percentage of medication orders entered by physician or } \\
\text { acute nurse practitioner (as per medical directives) counted } \\
\text { over total number of medications ordered }\end{array}$ & Data warehouse (Post) & $\begin{array}{l}\text { Promotion of direct physician/ } \\
\text { acute nurse practitioner } \\
\text { orders }\end{array}$ \\
\hline
\end{tabular}

+ - All samples and figures measured per medication order (not order sets). 
Table 2. Key results \& findings - measured indicators and metrics for the MOE/MAR Project

\begin{tabular}{|c|c|c|c|c|}
\hline Area of Impact & Metric/lndicator & Pre & Post & Result \\
\hline \multirow[t]{4}{*}{ Patient safety } & $\begin{array}{l}\text { Major ordering \& transcription } \\
\text { error \%* }\end{array}$ & $10.2 \%$ & $6 \%$ & $\begin{array}{l}42 \% \text { Decrease in major ordering \& } \\
\text { transcription errors detected* }\end{array}$ \\
\hline & $\begin{array}{l}\text { Minor ordering \& transcription } \\
\text { error \% * }\end{array}$ & $25.6 \%$ & $0 \%$ & $\begin{array}{l}\text { Elimination of all minor ordering } \\
\text { errors* }\end{array}$ \\
\hline & $\begin{array}{l}\text { Medication incident reporting } \\
\text { frequency }\end{array}$ & $\begin{array}{l}1.9 \text { reported } \\
\text { incidences per unit/ } \\
\text { month }\end{array}$ & $\begin{array}{l}4.8 \text { reported } \\
\text { incidences per unit/ } \\
\text { month }\end{array}$ & $\begin{array}{l}152 \% \text { Increase in reported } \\
\text { medication incidences }\end{array}$ \\
\hline & Transcription error reported & $\begin{array}{l}0.7 \\
\text { reported incidences } \\
\text { per unit/month }\end{array}$ & $\begin{array}{l}0.1 \\
\text { reported incidences } \\
\text { per unit/month }\end{array}$ & $\begin{array}{l}80 \% \text { Decrease in reported } \\
\text { transcription errors ** }\end{array}$ \\
\hline \multirow[t]{4}{*}{$\begin{array}{l}\text { Medication order } \\
\text { processing improvement }\end{array}$} & $\begin{array}{l}\text { Total medication order } \\
\text { processing cycle time }\end{array}$ & 180 minutes & 121 minutes & $\begin{array}{l}\text { Average decrease of } 59 \text { minutes or } \\
33 \%\end{array}$ \\
\hline & "Now" dose turnaround time & 106 minutes & 81 minutes & $\begin{array}{l}\text { Average decrease of } 25 \text { minutes or } \\
23 \%\end{array}$ \\
\hline & $\begin{array}{l}\text { Telephone \& verbal order } \\
\text { comparison }\end{array}$ & $11.2 \%$ & $2.8 \%$ & $\begin{array}{l}75 \% \text { Decrease in verbal \& telephone } \\
\text { orders }\end{array}$ \\
\hline & $\begin{array}{l}\text { MD co-signature rate } \\
\text { comparison }\end{array}$ & $42.6 \%$ & $96.8 \%$ & $\begin{array}{l}126 \% \text { Increase in MD co-signature } \\
\text { - near complete co-signed orders }\end{array}$ \\
\hline \multirow[t]{2}{*}{ Other benefits } & $\begin{array}{l}\text { Clinical decision support } \\
\text { utilization }\end{array}$ & N/A & 3,865 alerts/month & $\begin{array}{l}\text { Increased potential medication } \\
\text { ordering errors detected at order } \\
\text { entry per month }\end{array}$ \\
\hline & CPOE percentage & $\mathrm{N} / \mathrm{A}$ & $89 \%$ & $\begin{array}{l}\text { High compliance for direct prescriber } \\
\text { order entry }\end{array}$ \\
\hline
\end{tabular}

${ }^{*}$ Sampled orders for two months pre- and post-implementation on one General Medicine Unit - all samples and figures measured per medication order (not order sets).

** Complex medication orders remain on paper and are transcribed manually.

- All samples and figures measured per medication order (not order sets).

- Please refer to Table 1 for definition and data sources.

There were three areas where we could use the results for improvement. The first area was the current product/application, as we had identified improvement opportunities in the customization of the application to better suit the clinician needs. We were also able to identify clinical work improvements by taking advantage of the electronic capabilities not available on paper. As well, we were able to use the data to improve on our project implementation processes by making mid-course corrections, our status report card (as mentioned in the Project Management section) and allowing us to identify unreported issues by the users and resolving them in a timely manner.

\section{Challenges}

The initial challenge for us was securing executive commitment to conduct a benefits/measurement study. While there was general interest, there were also many questions from organization leaders about what it would cost, how much time it would take to complete and how many people would need to be involved. In addition, there was some scepticism about how quickly results would be available. To put all these issues in context, we returned to our initial question: How will we know whether the decision to invest time, people and money in MOE/MAR was worth it? We, UHN's senior leadership, and MOE/MAR leaders all recognized that the best way to answer these questions was to proceed with the study, using available financial resources and developing a detailed and time-bound project plan.

During steering committee meetings, another issue arose. The committee was made up of researchers, clinicians, administrators, academics and project managers. This mix of people and perspectives naturally led to a diversity of opinions on the 


\section{Lessons Learned}

\section{Measuring patient safety}

The benefits study was not intended to measure adverse drug events or to replicate the study by Baker et al. (2004). The results of the study do not demonstrate direct evidence that the system has saved lives but does however establish enough benefits to indicate a reduction in patient safety risks for medication therapy at UHN.

2. Utilizing results to influence process improvements and stakeholder buy-in

As an example, by timely measuring the effect of technology on the entire medication management process, the project team was able to quantify the collateral impacts of a partial system implementation strategy and quickly change course to implement both ordering and administering functionality together. Consistent communication findings also helped clinicians and hospital administrators understand long-term benefits despite initial challenges moving down the MOE/MAR learning curve.

\section{Unexpected and non-quantitative benefits realized}

Customized order-sets for each practice area promoted standardized and complete medication orders, which provided a better teaching environment for rotating clinical staff. MOE/MAR introduced a new level of accountability, resulting in increased medication incidence reporting and a major decrease in verbal and telephone orders - facilitating best-practice and policy adherence. MOE/MAR also increases clinician EPR interaction time, which encourages higher utilization of other pre-existing electronic charting modules.

\section{Managing expectations of results}

MOE/MAR will not reduce the amount of clinician time spent on medication ordering and processing; however, it will streamline and expedite the overall medication management process. Utilize both the positive and negative results - the positive to demonstrate system effectiveness - the negative to create changes that will improve the system. MOE/MAR will never be "perfect" - it will consistently require changes and enhancement with technological improvements and changing medication practices.

\section{Simplified and streamlined methodology}

Focus on the "useful" and meaningful indicators and metrics. Keep to a simple methodology to minimize human resources required and for ease of study repetition. Maximize electronic reporting capabilities and refrain from manual chart audit methodologies; this is clinicalresource intensive.

\section{Be aware of data collection issues before you begin} Ask the following questions: Is your system designed to extract the data you need? And do you have the personnel who know how to access this data? Finally, how do you plan to manage such a process?

7. Manage the expectations of the project steering committee Choose a diverse group of people to steer the project but plan for management of the differing expectations and agendas. Once overall objectives and research questions have been sorted out, create an operational group of four or five individuals, to manage the progress of the study and report back to the steering committee.

8. Secure executive commitment and sponsorship Before the project begins, clearly explain the value of a benefits/ measurement study and have it incorporated into project planning. Be firm and persistent in order to win over sceptics.

\section{Look for regional partners to cooperate on a study}

Finding other organizations in your area will help defray costs and maximize resources.

\section{Work with external experts}

Contact your local or regional university to seek out faculty leaders and students with research, systems analysis and experience with process and project management. purpose of the study, the attainability of the data and the value of the results that could be achieved. Managing these differing agendas was a significant challenge. Once a scope and focus for the study was determined, it was important to create a smaller operational group, made up of key members with commitment to the same vision. This group was responsible for monitoring the project and ensuring it stayed on track. In addition they would report back to the study steering committee to review quarterly and bi-annual findings.

We initially concentrated more of our efforts on the physician order entry impacts, as we had originally separated our project rollout to the MOE component only to help manage the implementation workload. However, our study had quickly identified serious process issues that come with an electronic MOE and a manual paper MAR system. This identification led the project team to revise their rollout schedule after the initial cluster implementation decision to include both MOE and MAR functionalities simultaneously. As a result, this corrected the hybrid process issues and helped realize the benefits of using both modules together.

Another major challenge was extracting data from UHN and SIMS' electronic reporting systems from which we could make decisions about the indicators we would use as measures. Generating data took months. And when we did produce data, we questioned the usefulness and quality. The electronic reporting system simply was not designed for this purpose. Most hospital information systems do not support process improvement activities; rather they focus on clinical and finance reporting. Many of the reporting and data sources for this study had to be customized and required periods of time to be ready. One challenging example was the medication timing report, which included order, verification and administration time. This may also be an issue for other organizations interested in conducting a similar study.

Finally, it is also essential to recruit people with a solid knowledge of process as well as analytical and problemsolving skills (not merely data collection or data entry skills). We were fortunate that our team had these core competencies. A study like this requires individuals who know how to interpret data. In short, professionals with research experience - as well as systems analysis skills - are essential to the project's well-being.

\section{After the Study - Should We Continue?}

What began as a research study has now evolved into a framework for how people do their work on a daily basis. While the MOE/MAR implementation has been completed, UHN continues to internally study the 
results, submitting reports to senior administration and clinical leaders throughout the hospital network.

The plan over the next year is to continue to incorporate the key lessons from this project into a continuous cycle of planning for other information technology-based projects at UHN.

\section{References}

Baker, G.R., P. Norton, V. Flintoft, R. Blais, A. Brown, J. Cox, E. Etchells, W. Ghali, P. Hébert, S. Majumdar, M. O’Beirne, L. PalaciosDerflinger, R. Reid, S. Sheps and R. Tamblyn. 2004. "The Canadian Adverse Events Study: The Incidence of Adverse Events Among Hospital Patients in Canada." Canadian Medical Association Journal 170: $1678-86$.

Institute for Healthcare Improvement. 2006. Testing Changes. Retrieved September 12, 2006. <http://www.ihi.org/IHI/Topics/Improvement/ ImprovementMethods/HowToImprove/testingchanges.htm>.

\section{About the Authors}

Nicholas Zamora, BSc(Pharm), MBA., CHE, is a management consultant with The Courtyard Group Ltd.

Michael Carter is an Adjunct Scientist at ICES, a Professor in the Department of Mechanical and Industrial Engineering at the University of Toronto and Director of the Healthcare Resource Modelling Lab. He is on the editorial board for the Journal of Scheduling and the journal Health Care Management Science.

Stephanie Saull-McCaig is the Director of Acute Care Information Management, Shared Information Management Services (SIMS) at University Health Network.

Joe Nguyen is an Industrial Engineer in Shared Information Management Services at University Health Network. Contact: joe.nguyen@uhn.on.ca

\section{Commentary}

The Benefits and Impacts of the MOE/MAR Implementation: A Quantitative Approach

\section{Denis Protti}

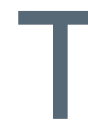

his paper describes how $\mathrm{UHN}$ was able to determine if the MOE/MAR project accomplished its stated objectives of improving patient safety and the medication ordering and processing cycle. Though the authors qualify that the benefits study was not intended to measure adverse drug events or to replicate the 2004 study by Baker et al., the findings do add new evidence that MOE/MAR does indeed reduce ordering and transcription errors and reduce medication incidences.

These UHN findings are particularly significant, since other recent evidence suggests that, despite the growing use of error reporting tools, the healthcare industry is inexperienced in receiving, understanding and analyzing these reports. A recent Johns Hopkins study (Miller et al. 2006) found that, despite clear imperfections in the data captured, medication error reporting tools are effective as a means of collecting reliable information on errors rapidly and in real time. Their data suggest that administration errors are at least as common as prescribing errors in children.

Miller et al. (2006) found that, of the 1,010 medication errors reviewed, $30 \%$ were prescribing errors, $24 \%$ were dispensing errors, $41 \%$ were administration errors and only $6 \%$ involved medication administration records (MAR). About one-third of the medication error reports needed to have the subtype of error reclassified; $59 \%$ of these involved the reporter choosing the non-descript "other" category on the reporting tool (such as "prescribing other"), which was able to be reclassified by expert review. The overall distribution of error type categories did not change significantly with expert review, although only MAR errors were underreported by the reporters. The most common medications were anti-infectives (17\%), pain/sedative agents $(15 \%)$, nutritional agents $(11 \%)$, gastrointestinal agents $(8 \%)$ and cardiovascular agents (7\%).

Whenever the subject of errors comes up, one is reminded of Morgan's 2004 paper, "In Pursuit of a Safe Canadian Healthcare System." In it, he asked: Are Canadian patients safer today? Has the national rate of medical errors decreased? Are fewer hospitalized patients in Canada dying from medical errors? Are Canadians less likely to experience an adverse drug event in the outpatient setting? Is our growing home care delivery safe? Are diagnostic investigations being performed in a timely and effective manner? Are the right patients being treated with the right medications in the right dosages for the right duration? Are patients achieving the expected and desired outcomes?

The recent Johns Hopkins paper suggests that further research is needed, not only in the area of computerized physician order entry (CPOE) for children, but also on ways to make the dispensing and administration of medications safer. Undoubtedly, the same applies to the UHN and other adult hospitals introducing medication order entry and medical administration record systems. However, thanks to the efforts underway at UHN and other leading facilities, can we say that some of Morgan's questions are being answered?

\section{References}

Miller, M.R. , J.S. Clark and CU Lehmann. 2006. "Computer Based Medication Error Reporting: Insights and Implications." Quality and Safety in Health Care 15: 208-13.

Morgan, M.W. 2004. "In Pursuit of a Safe Canadian Healthcare System.” HealthcarePapers 5(3): 10-28.

\section{About the Author}

Denis Protti is a Professor, School of Health Information

Science, University of Victoria. 